\title{
THE HUNDREDTH ANNIVERSARY OF THE CAMBRIDGE ENTOMOLOGICAL CLUB
}

The Cambridge Entomological Club, founded on January 9, I874, will celebrate its Iooth anniversary at a Centennial Meeting, Tuesday, April 9, 1974. As part of the celebration, Professor Thomas Eisner of Cornell University will deliver the Centennial Lecture on Monday, April 8, at 5 p.m., in the main lecture room, Biological Laboratories (Divinity Ave.), Cambridge. On Tuesday at 4 p.m. the entomological section (4th floor) of the Museum of Comparative. Zoology and the new M.C.Z. Laboratories will hold open house for Club members and visiting entomologists. The Centennial Meeting on Tuesday will be held at the Harvard Faculty Club, Quincy Street, Cambridge, at 6 p.m. Visiting entomologists are cordially invited to attend both the Lecture and the Meeting, provided that arrangements are made in advance with the secretary of the Entomological Club.

The March number of the Club's journal, Psyche, which began publication in May, I874, has been designated the Centennial Issue and will contain, among other articles, a history of the Club.

-F. M. Carpenter, editor 

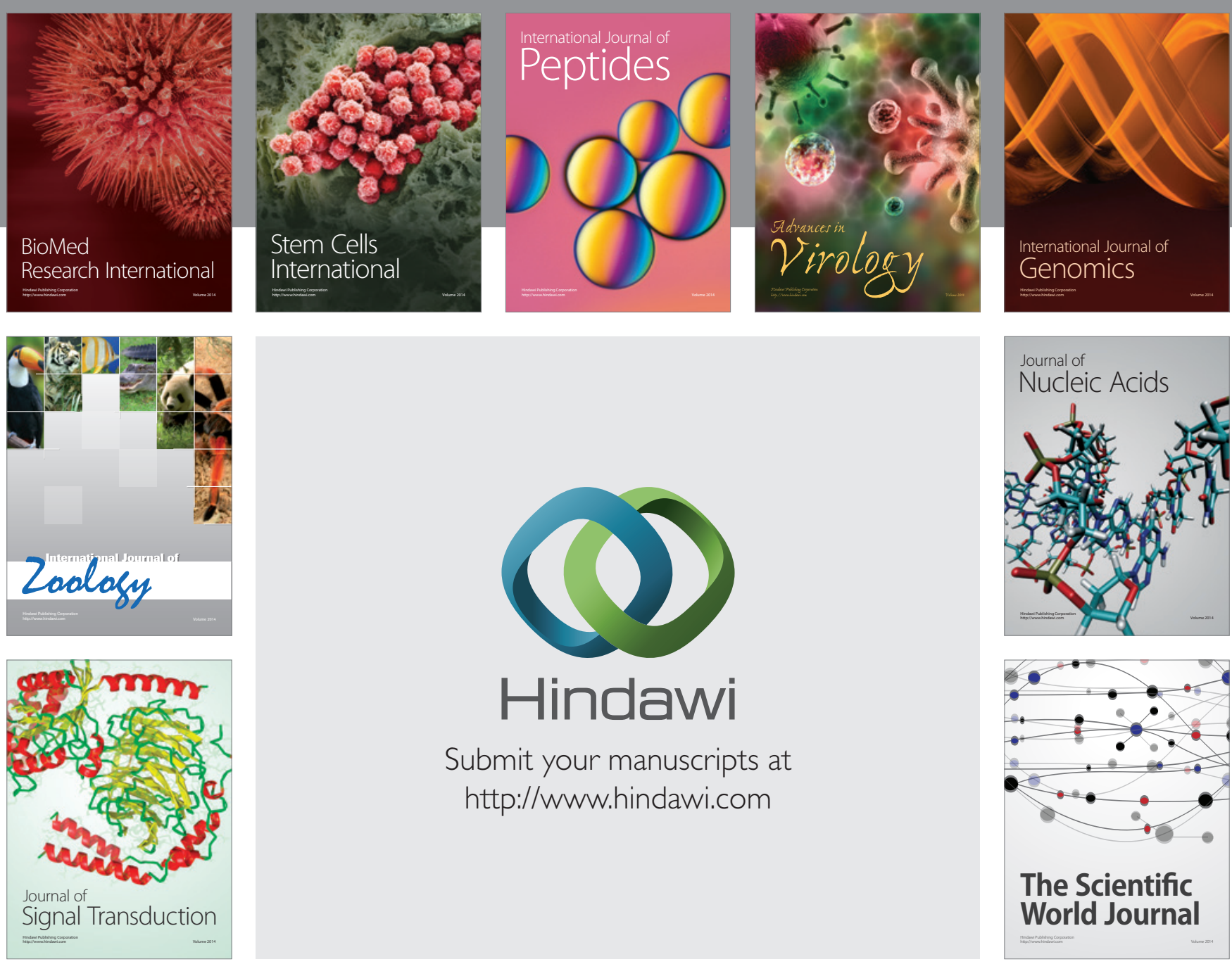

Submit your manuscripts at

http://www.hindawi.com
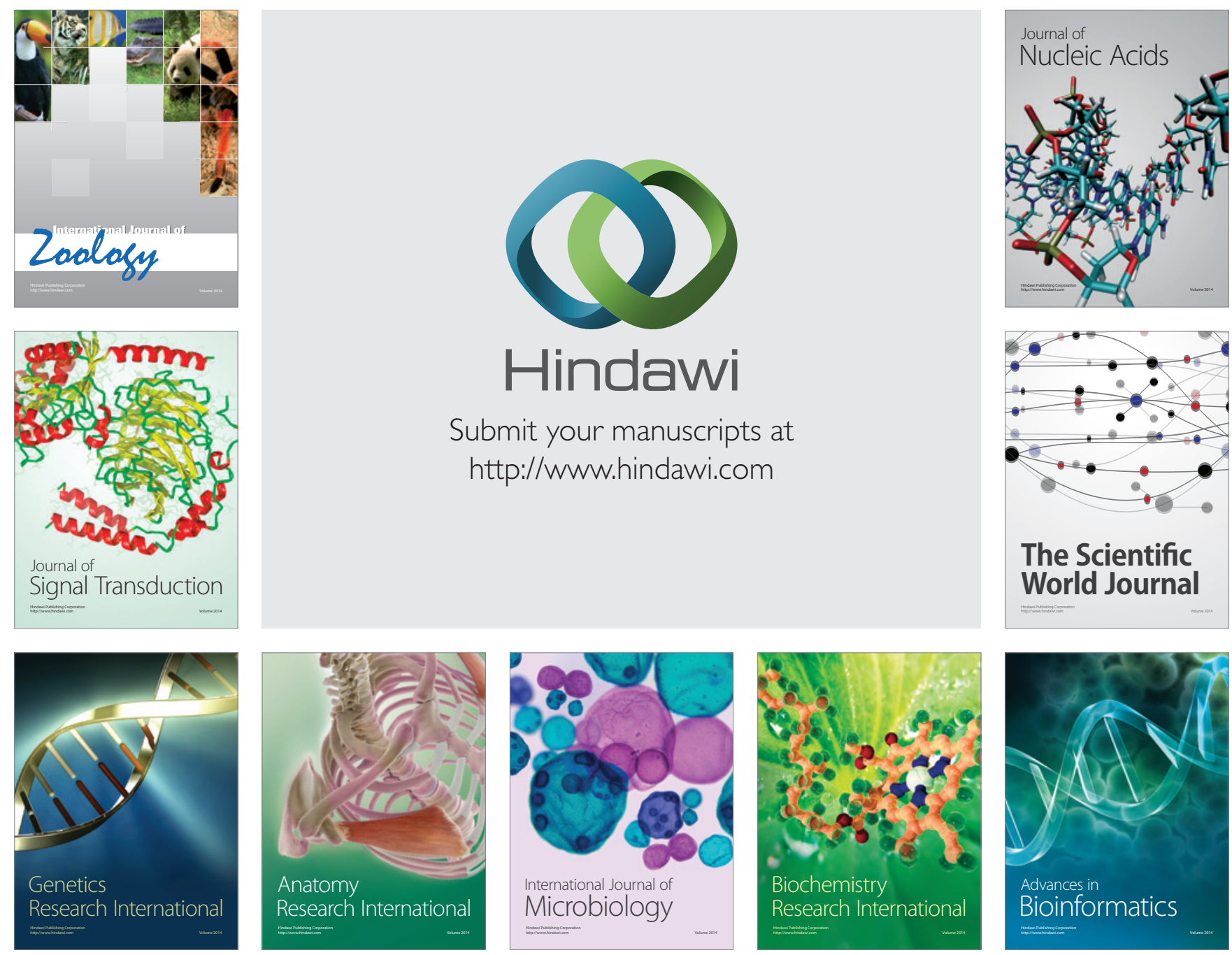

The Scientific World Journal
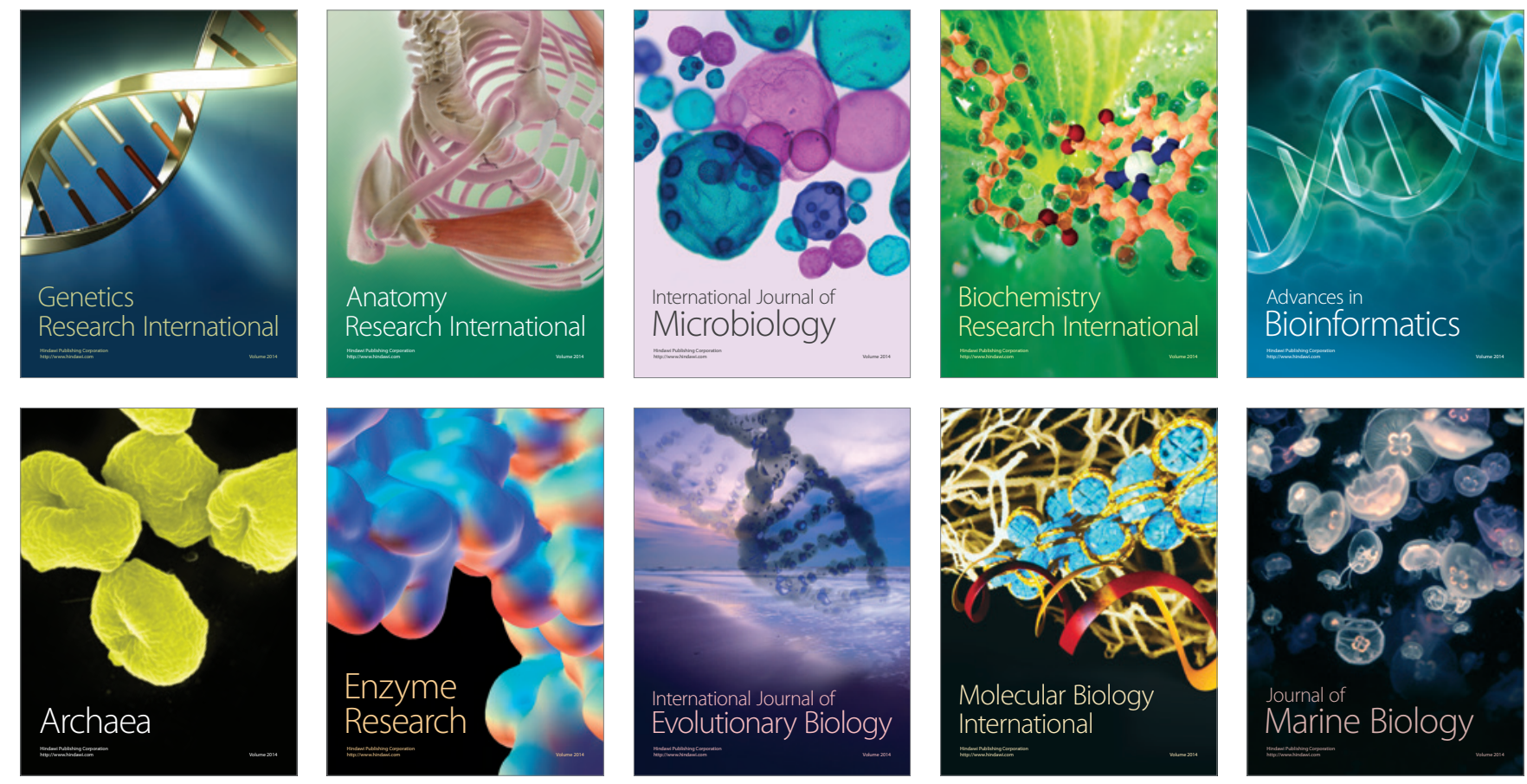